\title{
A Complicated Case of Tacrolimus- Induced Rapid Remission after Cesarean Section in the Early Third Trimester for Refractory Severe Ulcerative Colitis Flaring in the Initial Period of Gestation
}

\author{
Takashi Mizushima Satoshi Tanida Tsutomu Mizoshita \\ Yoshikazu Hirata Kenji Murakami Takaya Shimura \\ Hiromi Kataoka Takeshi Kamiya Takashi Joh \\ Department of Gastroenterology and Metabolism, Nagoya City University \\ Graduate School of Medical Sciences, Nagoya, Japan
}

\section{Key Words}

Ulcerative colitis · Pregnancy · Tacrolimus · Intensive granulocyte and monocyte adsorptive apheresis - Cesarean section

\begin{abstract}
A 36-year-old woman who had been diagnosed with ulcerative colitis at the age of 17 years was referred to our hospital because of severe abdominal pain and repeated bloody diarrhea that persisted during pregnancy despite combination therapy with high-dose corticosteroids and weekly granulocyte and monocyte adsorptive apheresis (GMA). She underwent combination therapy consisting of high-dose corticosteroids, intensive GMA (two sessions per week) and vancomycin, which was used to eradicate Clostridium difficile, under total parenteral nutrition control until the estimated weight of her fetus reached $1,000 \mathrm{~g}$. This combination therapy was partially successful, resulting in almost complete disappearance of abdominal pain and a marked decrease in stool frequency. However bloody diarrhea persisted and the patient developed anemia and hypoalbuminemia and was unable to prolong her gestation time. Cesarean section was conducted at 28 weeks of gestation without any congenital abnormalities or neurological defects. Oral administration of tacrolimus was begun 7 days after cesarean section, which was followed by rapid induction of remission. Corticosteroids were then gradually tapered off. Tacrolimus is one therapeutic option after cesarean section in pregnant patients who do not respond well to GMA and high-dose corticosteroids for persistent active ulcerative colitis.
\end{abstract}




\begin{tabular}{c|l|l|l}
$\begin{array}{r}\text { Case Reports in } \\
\text { Gastroenterology }\end{array}$ & $\begin{array}{l}\text { Case Rep Gastroenterol 2011;5:144-151 } \\
\text { DOI: 10.1159/000326938 }\end{array}$ & $\begin{array}{l}\text { Published online: } \\
\text { April 12, 2011 }\end{array}$ & $\begin{array}{l}\text { O 2011 S. Karger AG, Basel } \\
\text { ISSN 1662-0631 } \\
\text { www.karger.com/crg }\end{array}$ \\
\hline
\end{tabular}

\section{Introduction}

The prevalence of ulcerative colitis (UC) has increased each year for the past several decades. Patients with UC clinically display a recurrence-remission cycle. A large-scale population-based cohort study shows that the flare-up rate in women is 1.2 times higher than that in men. Accordingly, female gender appears to be a risk factor for frequent UC flare-up [1]. Female patients often suffer from UC symptoms during pregnancy as UC symptoms generally start to appear then, and a definitive diagnosis of UC has been confirmed in younger individuals in their teens to thirties. It has been estimated that approximately $25 \%$ of female UC patients conceive after UC diagnosis [2]. In addition, the risk of flare-up and the development of associated inflammation during pregnancy is known to be increased in both the remission and the active stages of inflammatory bowel diseases (IBD), including UC and Crohn's disease [3]. The first trimester is considered to be a particularly high-risk time for flare-up of UC. In contrast, two European cohort studies of 634 pregnancies in 303 women showed that pregnancy improves the disease course, with a reduction in flare-ups in subsequent years $[2,4]$.

Therapeutic options are limited when flare-ups occur during pregnancy due to the concerns for the safety of fetus. According to previous reports and statements by the United States Food and Drug Administration (FDA) (http://www.fda.gov/Drugs/ DevelopmentApprovalProcess/DevelopmentResources/Labeling/ucm093307.htm), 5-aminosalicylic acid (5-ASA), corticosteroids and granulocyte and monocyte adsorptive apheresis (GMA; Adacolumn ${ }^{\circledR}$ ) have been proven to be safe and are recommended treatments during pregnancy [5]. However, we have often observed UC that is refractory to individual treatment with these drugs or with this modality, or to intensive therapeutic approaches that combine these drugs with this modality.

Intensive GMA involving two GMA sessions per week has recently been shown to be more efficacious than conventional weekly GMA. Furthermore, intensive GMA also safely induced rapid remission in patients with moderately active UC inflammation [6]. Very recently, the drug tacrolimus was approved in Japan for the treatment of patients with moderate or severe UC, regardless of whether the UC is dependent on or refractory to corticosteroids. Tacrolimus is reportedly useful for the treatment of refractory UC due to its potent immunosuppressive properties, which induce inhibition of the transcription of the early activation genes encoding interleukin-2, tumor necrosis factor- $\alpha$ (TNF- $\alpha$ ) and interferon- $\gamma$ that are responsible for the development of inflammation [7]. We report herein the case of a patient with severe UC that had developed during the first trimester of pregnancy and was refractory to combination therapy with high-dose corticosteroids and intensive GMA, but was successfully treated with tacrolimus following cesarean section early in the third trimester.

\section{Case Report}

In July 2009, a 36-year-old pregnant woman was referred to our hospital for treatment of refractory UC. She had been diagnosed with UC (total colitis) at the age of 17 . Oral 5-ASA $(2,250 \mathrm{mg} /$ day) had maintained her in remission up to the age of 31. Subsequently, repeated flare-ups had occurred and she had been treated with corticosteroids or with the routine weekly GMA. Azathioprine (AZA) administration was also tried, but had to be stopped due to AZA-induced pancytopenia. Then, oral 5 -ASA (2,250 $\mathrm{mg} /$ day) plus $3 \mathrm{mg}$ betamethasone enema had induced and maintained remission up to 


\begin{tabular}{c|l|l|l}
$\begin{array}{r}\text { Case Reports in } \\
\text { Gastroenterology }\end{array}$ & $\begin{array}{l}\text { Case Rep Gastroenterol 2011;5:144-151 } \\
\text { DOI: 10.1159/000326938 }\end{array}$ & $\begin{array}{l}\text { Published online: } \\
\text { April 12, 2011 }\end{array}$ & $\begin{array}{l}\text { O 2011 S. Karger AG, Basel } \\
\text { ISSN 1662-0631 } \\
\text { www.karger.com/crg }\end{array}$ \\
\hline
\end{tabular}

2008. In April 2009, at the age of 36 years, she became intentionally pregnant for the first time, while her UC was in remission with oral 5-ASA at a dose of 2,250 mg daily.

However, during pregnancy, the flare-up of her total colitis required daily intravenous administration of up to $80 \mathrm{mg} /$ day prednisolone, oral 5-ASA 2,250 mg/day and weekly GMA for 10 weeks, followed by weekly lymphocytapheresis for 3 weeks under the management of a total parenteral nutrition program at the previous hospital. She underwent a blood transfusion due to the development of bloody bowel movements, which was followed by severe anemia with less than $8 \mathrm{~g} / \mathrm{dl}$ of hemoglobin. Antigenemia (C7-HRP) positivity against cytomegalovirus was transiently detected and subsequently spontaneously converted into a negative response. There was hardly any improvement in the patient's condition following these treatments.

After referral to our hospital, the patient was orally administered $20 \mathrm{mg}$ prednisolone and 2,250 $\mathrm{mg}$ mesalamine on a daily basis. Physical examination revealed lower abdominal tenderness with repeated bloody stools (8-10 times a day). Her temperature was $37.5^{\circ} \mathrm{C}$, and her heart rate was $113 \mathrm{beats} / \mathrm{min}$. Laboratory investigations revealed a white blood cell count of $9,900 / \mu \mathrm{l}$, hemoglobin $10.1 \mathrm{~g} / \mathrm{dl}$, C-reactive protein $2.41 \mathrm{mg} / \mathrm{dl}$, serum albumin $2.9 \mathrm{~g} / \mathrm{dl}$ and an erythrocyte sedimentation rate of $50 \mathrm{~mm} / \mathrm{h}$ (table 1 ). Negative results were obtained for C7-HRP. A first sigmoidoscopy showed several deep longitudinal ulcerations with erythematous and edematous changes in the mucosa from the rectum to the sigmoid colon (fig. 1a). Immunohistochemical findings and a polymerase chain reaction analysis of cytomegalovirus in colon biopsy specimens were also negative. Upon discussion of the remaining therapeutic options, the patient refused proctocolectomy and ileoanal pouch anastomosis and chose to continue her pregnancy. She was first maintained on $20 \mathrm{mg}$ prednisolone and 2,250 mg 5-ASA daily; these doses were increased to $40 \mathrm{mg}$ predonisolone and 4,000 $\mathrm{mg}$ 5-ASA daily in addition to $500 \mathrm{mg}$ vancomycin daily for 1 week because of little improvement and stool culture positivity of Clostridium difficile (though cultures were negative for $C$. difficile toxin). This treatment successfully eliminated the C. difficile positivity of stool culture. The patient also underwent intensive GMA therapy (two sessions weekly), which was partially successful, resulting in almost complete disappearance of abdominal pain and a decrease in bowel movements to 3-5 times daily. However, her anemia was little improved and there was a gradual development of hypoalbuminemia to such an extent that transfusion of albumin was necessary every other day in order to maintain the serum level at $3.0 \mathrm{mg} / \mathrm{dl}$, the recommended level for healthy development and safe delivery of a child. She was consequently unable to attain a further prolonged gestation and feared risks of blood-borne infections like hepatitis B, hepatitis C or AIDS viruses by repeated frequent blood transfusions. Her first baby was prematurely delivered by cesarean section at 28 weeks and 1 day on September 9 (birth weight 1,008 g, length $35 \mathrm{~cm}$ ) without any congenital malformations or neurological abnormalities.

After cesarean section, the patient was started on oral tacrolimus (Prograf ${ }^{\circledR}$ ), aiming for serum trough levels of $10-15 \mathrm{ng} / \mathrm{ml}$ for 2 weeks, followed by tapered serum trough levels of 5-10 ng/ml. Her condition quickly improved in the following weeks and complete remission was achieved by tapering the prednisolone dose. Total colonoscopy showed scattered regenerating areas with faintly erythematous changes in the mucosa of the transverse colon and the rectum and the appearance of mucosal healing at other sites 3 months after oral tacrolimus administration was started (fig. $1 \mathrm{~b}$ ). Tacrolimus is not currently approved in Japan for maintenance therapy, and therefore tacrolimus administration was stopped. Nine months later, the patient continued to be in stable remission (fig. 2 ).

\section{Discussion}

In clinical settings, therapeutic treatment for UC flare-up during pregnancy is limited because of concerns for the safety of the unborn child. We report herein the case of a patient with flared refractory UC during pregnancy who underwent a bridging therapy consisting of high-dose corticosteroids combined with intensive GMA until it was impossible to prolong gestation any further. At that point, cesarean section was performed and the patient was successfully treated with tacrolimus.

The incidence rates of flare-up and the development of UC during pregnancy reach approximately $30 \%$ during both the remission and the active stages [3]. However, it has 
been reported that there is no evidence to suggest that pregnancy increases the relapse risk for patients with UC $[2,4]$. There is also some evidence to show that pregnancy has a favorable effect on UC over time. A retrospective study of 111 IBD patients showed that increased parity is associated with a reduction in surgical resections [8]. Thus, while relapses do occur in pregnant patients, such episodes are apparently not more frequent than those in non-pregnant individuals. The key point regarding whether UC will re-emerge during pregnancy or not is the degree of activity of UC at the time of conception. Therefore, although the present case was in remission at the time of conception, this remission may not have involved complete mucosal healing.

Anti-inflammatory and immunomodulatory medications are indispensable in the management of UC. Currently used medications, such as corticosteroids, purine analogues, cyclosporine, tacrolimus and anti-TNF blockers, are all associated with an increased risk of opportunistic infection. Multivariate analysis of a recent case-control study performed in IBD patients showed that the use of corticosteroids increased the likelihood of opportunistic infection with a calculated odds ratio of approximately 4 compared with the use of mesalamine [9]. Numerous studies have described an association between opportunistic enteric infections and exacerbation or relapse of UC. Pathogens involved as potential triggers of UC flare-ups include C. difficile,

Campylobacter spp., Escherichia coli, and cytomegalovirus. In particular, the risk of C. difficile-associated diarrhea is increased, not only by antibiotic exposure, but also by immune-compromising conditions in IBD patients, and there is therefore a strong focus on this risk during UC flare-ups. C. difficile-associated colitis in patients with IBD has a higher mortality than that in patients with C. difficile without a background of IBD. Although neither toxin A nor B was detected in the present case, we eradicated C. difficle as a precautionary measure. This treatment resulted in a partial response with 2-3 times fewer daily bowel movements than prior to eradication, suggesting that $C$. difficile infection might indeed be involved in the exacerbation of UC disease activity. Repeated stool cultures and toxin analyses of $C$. difficile after eradication gave a negative result as did analysis of C7-HRP.

Pharmacologic management of UC currently relies on 5-ASA, corticosteroids, immunomodulators (AZA and 6-mercaptopurine (6-MP)), calcineurin inhibitors (cyclosporine and tacrolimus), and TNF blockade. Regarding medication during pregnancy, the most important point is to maintain remission and inactivation of disease, since the greatest risk to pregnancy is active disease. Another key principle to disease management during UC flare-up is to remember that therapeutic treatment is limited due to concerns regarding potential fetal complications. 5-ASA remains the first-line therapy for induction and maintenance of remission for patients with mild to moderately active UC, based on an extensive history of efficacy and safety. Prospective controlled trials and a population-based cohort study of pregnant patients who had been exposed to mesalamine did not suggest that 5-ASA posed an increased risk to the fetus, despite the fact that mesalamine and its metabolite, acetyl 5-ASA, are found in cord plasma [10].

Corticosteroid therapy is a well-established and effective treatment for patients with active UC. A large case-control study and a meta-analysis of the use of corticosteroids during the first trimester of pregnancy reported an increased risk of oral clefts in the newborns with an odds ratio of 3.35 (95\% confidence interval 1.97-5.69) and a low overall risk of major malformations with an odds ratio of 1.45 (95\% confidence interval $0.8-2.60$ ) [11]. Gestational diabetes is also a concern when using corticosteroids. 


\begin{tabular}{l|l|l|l}
$\begin{array}{r}\text { Case Reports in } \\
\text { Gastroenterology }\end{array}$ & $\begin{array}{l}\text { Case Rep Gastroenterol 2011;5:144-151 } \\
\text { DOl: 10.1159/000326938 }\end{array}$ & $\begin{array}{l}\text { Published online: } \\
\text { April 12, 2011 }\end{array}$ & $\begin{array}{l}\text { O 2011 S. Karger AG, Basel } \\
\text { ISSN 1662-0631 } \\
\text { www.karger.com/crg }\end{array}$ \\
\hline
\end{tabular}

Intensive leukocytapheresis (Adacolumn, JIMRO and Cellsorba; Asahi Medical Company, Tokyo, Japan) is a relatively safe procedure that is widely used in Japan for the treatment of active UC [6]. No reports have indicated an increased incidence of fetal abnormalities associated with the procedure. A case report of a patient with UC at one center reported that GMA was effective for severe UC by inducing remission with no fetal complications [5].

Immunosuppressive therapy using AZA or 6-MP is sometimes useful for maintenance of remission in UC. Pregnant patients treated with AZA or 6-MP for IBD showed no incidence of pregnancy complications or congenital malformations. A cohort study that investigated the pregnancy outcome in female patients with Crohn's disease showed a higher rate of congenital anomalies following antenatal exposure to AZA compared with non-treated patients [12]. Thus, the safety of AZA and 6-MP in the treatment of pregnant patients with IBD remains controversial.

Tacrolimus and cyclosporine are efficacious treatments for induction of remission of refractory UC [7]. One report that investigated 100 pregnancies among transplant recipients showed a $68 \%$ live birth rate, $12 \%$ spontaneous abortion, $3 \%$ stillbirth, and $59 \%$ premature delivery [13]. In contrast, a case report of a patient with UC described a successful pregnancy and delivery of a healthy baby with rapid remission and long-term maintenance [14]. A meta-analysis of 15 studies of pregnancy outcomes after cyclosporine therapy reported no statistical difference in the rate of fetal malformations compared to that among the general population [15].

A rapid clinical response to a TNF- $\alpha$ inhibitor (infliximab) is obtained when this inhibitor is used for the treatment of UC. Infliximab does not cross the placenta in the first trimester, but feasibly is likely to do so in the second and third trimesters, thus protecting the infant from infliximab exposure during the crucial period of organogenesis. This result suggests that infliximab treatment does not pose a significant risk of complications during pregnancy.

The use of AZA/6-MP, tacrolimus or cyclosporine during pregnancy has never been permitted in Japan. Furthermore, until June 2010, infliximab treatment was not approved for treatment of active UC. Thus, infliximab could not be applied for this patient at that time.

Based on all of the above, we ultimately selected the following treatment regime: bridging therapy using 5-ASA, corticosteroids, and intensive GMA until it was impossible to further prolong gestation followed by a rescue therapy using tacrolimus after cesarean section. However, we should have had a way to select therapeutic treatment of infliximab. This therapy ultimately resulted in clinical remission.

In conclusion, for pregnant UC patients, combined therapy consisting of high-dose corticosteroids and intensive GMA is recommended until it is impossible to prolong gestation any further. When clinical remission cannot be obtained, rescue therapy using tacrolimus after cesarean section may be useful.

\section{Disclosure Statement}

The authors declare that no financial or other conflict of interests exists in relation to the content of this paper. 


\begin{tabular}{l|l|l|l}
$\begin{array}{r}\text { Case Reports in } \\
\text { Gastroenterology }\end{array}$ & $\begin{array}{l}\text { Case Rep Gastroenterol 2011;5:144-151 } \\
\text { DOI: 10.1159/000326938 }\end{array}$ & $\begin{array}{l}\text { Published online: } \\
\text { April 12, 2011 }\end{array}$ & $\begin{array}{l}\text { O 2011 S. Karger AG, Basel } \\
\text { ISSN 1662-0631 } \\
\text { www.karger.com/crg }\end{array}$ \\
\hline
\end{tabular}

Table 1. Laboratory findings

\begin{tabular}{lll}
\hline & & \\
& & Normal range \\
\hline Hematology & $9,900 / \mu \mathrm{l}$ & \\
WBC & $345 \times 10^{4} / \mu \mathrm{l}$ & $3,000-8,500$ \\
$\mathrm{RBC}$ & $10.1 \mathrm{~g} / \mathrm{dl}$ & $378-499 \times 10^{4}$ \\
$\mathrm{Hb}$ & $32.7 \%$ & $10.8-14.9$ \\
$\mathrm{Ht}$ & $282 \times 10^{3} / \mu \mathrm{l}$ & $35.6-45.4$ \\
$\mathrm{Plt}$ & $50 \mathrm{~mm} / \mathrm{h}$ & $150-361 \times 10^{3}$ \\
ESR & & $<15$ \\
Serum biochemistry & $5.5 \mathrm{~g} / \mathrm{dl}$ & \\
TP & $2.9 \mathrm{~g} / \mathrm{dl}$ & $6.7-8.3$ \\
Alb & $17 \mathrm{U} / \mathrm{l}$ & $4.0-5.0$ \\
GOT & $27 \mathrm{U} / \mathrm{l}$ & $13-33$ \\
GPT & $115 \mathrm{U} / \mathrm{l}$ & $6-27$ \\
CHE & $7 \mathrm{mg} / \mathrm{dl}$ & $214-466$ \\
BUN & $0.3 \mathrm{mg} / \mathrm{dl}$ & $8-22$ \\
Cre & $140 \mathrm{mEq} / \mathrm{l}$ & $0.4-0.7$ \\
Na & $3.9 \mathrm{mEq} / \mathrm{l}$ & $138-146$ \\
K & $101 \mathrm{mEq} / \mathrm{l}$ & $3.6-4.9$ \\
Cl & $2.41 \mathrm{mg} / \mathrm{dl}$ & $99-109$ \\
CRP & & $<0.30$ \\
Stool culture & $(+)$ & \\
C. difficile & $(-)$ & \\
Toxin A & $(-)$ & \\
Toxin B & $(-)$ & \\
Cytomegalovirus & & \\
C7-HRP & & \\
\hline
\end{tabular}
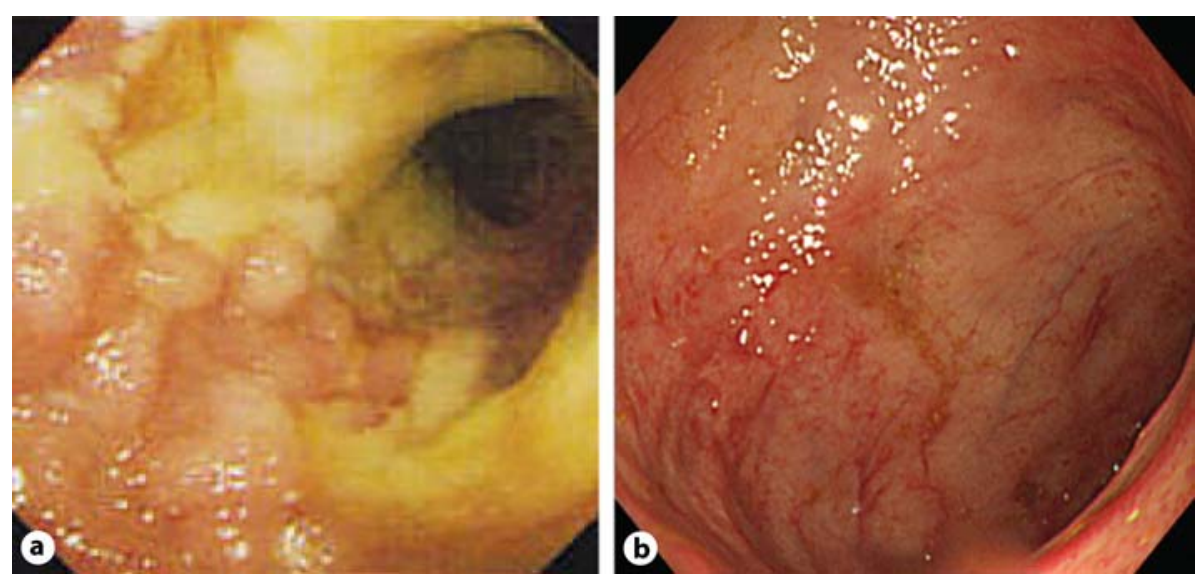

Fig. 1. Colonoscopy before and after treatment of a pregnant case complicated by active UC during gestation time. a The first sigmoidoscopy showed several deep longitudinal ulcerations with erythematous and edematous changes in the mucosa from the rectum to the sigmoid colon. Mucosal vascular patterns are not visible. $\mathbf{b}$ The second colonoscopy showed receding of the erythematous lesions in the transverse colon and the rectum and healing in the mucosa at the other sites. Mucosal vascular patterns are partially visible. 


\begin{tabular}{l|l|l|l}
$\begin{array}{r}\text { Case Reports in } \\
\text { Gastroenterology }\end{array}$ & $\begin{array}{l}\text { Case Rep Gastroenterol 2011;5:144-151 } \\
\text { DOI: 10.1159/000326938 }\end{array}$ & $\begin{array}{l}\text { Published online: } \\
\text { April 12, 2011 }\end{array}$ & $\begin{array}{l}\text { O 2011 S. Karger AG, Basel } \\
\text { ISSN 1662-0631 } \\
\text { www.karger.com/crg }\end{array}$ \\
\hline
\end{tabular}

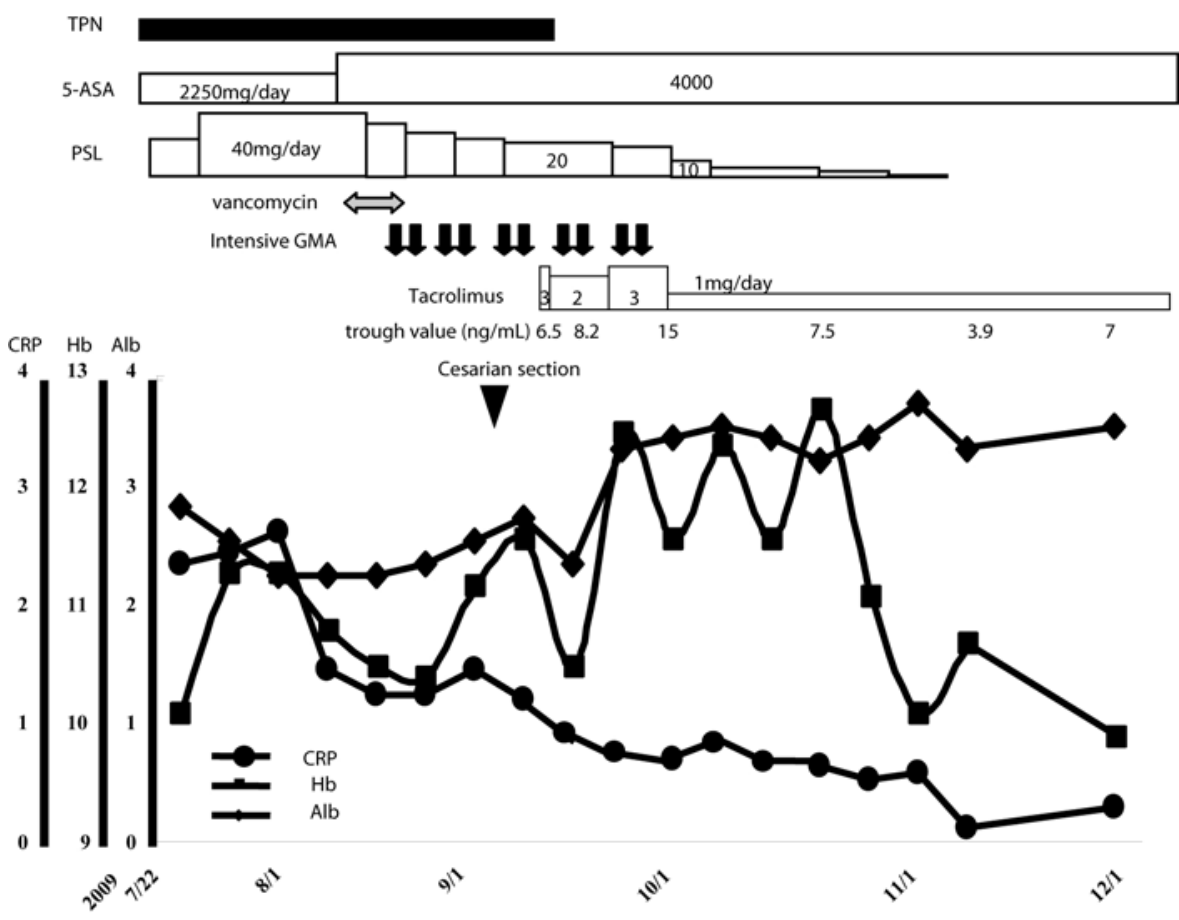

Fig. 2. Clinical course. The present case with flared refractory UC during pregnancy underwent bridging therapy consisting of high-dose corticosteroids combined with intensive GMA until it was impossible to prolong gestation any further and was subsequently successfully treated with tacrolimus after cesarean section.

\section{References}

1 Hoie O, Wolters F, Riis L, Aamodt G, Solberg C, Bernklev T, Odes S, Mouzas IA, Beltrami M, Langholz E, Stockbrugger R, Vatn M, Moum B: Ulcerative colitis patient characteristics may predict 10-yr disease recurrence in a European-wide population-based cohort. Am J Gastroenterol 2007;102:1692-1701.

2 Riis L, Vind I, Politi P, Wolters F, Vermeire S, Tsianos E, Freitas J, Mouzas I, Ruiz Ochoa V, O'Morain C, Odes S, Binder V, Moum B, Stockbrugger R, Langholz E, Munkholm P: Does pregnancy change the disease course? A study in a European cohort of patients with inflammatory bowel disease. Am J Gastroenterol 2006;101:1539-1545.

3 Miller JP: Inflammatory bowel disease in pregnancy: a review. J R Soc Med 1986;79:221-225.

4 Castiglione F, Pignata S, Morace F, Sarubbi A, Baratta MA, D’Agostino L, D’Arienzo A, Mazzacca G: Effect of pregnancy on the clinical course of a cohort of women with inflammatory bowel disease. Ital J Gastroenterol 1996;28:199-204.

5 Tsukada Y, Nakamura M, Nakao M, Suzuki T, Matsuo N, Yamamoto R, Hamaguchi A, Hanaoka K, Wakabayashi Y, Ogura M, Yokoyama K, Hosoya T: Therapeutic efficacy of granulocytapheresis in a pregnant woman with severe active ulcerative colits: a case report (in Japanese with English abstract). J Jpn Soc Dial Therapy 2007;40:871-875.

-6 Sakuraba A, Motoya S, Watanabe K, Nishishita M, Kanke K, Matsui T, Suzuki Y, Oshima T, Kunisaki R, Matsumoto T, Hanai H, Fukunaga K, Yoshimura N, Chiba T, Funakoshi S, Aoyama N, Andoh A, Nakase H, Mizuta Y, Suzuki R, Akamatsu T, Iizuka M, Ashida T, Hibi T: An open-label prospective randomized multicenter study shows very rapid remission of ulcerative colitis by intensive granulocyte and monocyte adsorptive apheresis as compared with routine weekly treatment. Am J Gastroenterol 2009;104:2990-2995.

7 Ogata H, Matsui T, Nakamura M, Iida M, Takazoe M, Suzuki Y, Hibi T: A randomised dose finding study of oral tacrolimus (FK506) therapy in refractory ulcerative colitis. Gut 2006;55:1255-1262.

8 Nwokolo CU, Tan WC, Andrews HA, Allan RN: Surgical resections in parous patients with distal ileal and colonic Crohn's disease. Gut 1994;35:220-223. 


\begin{tabular}{l|l|l|l}
$\begin{array}{r}\text { Case Reports in } \\
\text { Gastroenterology }\end{array}$ & $\begin{array}{l}\text { Case Rep Gastroenterol 2011;5:144-151 } \\
\text { DOl: 10.1159/000326938 }\end{array}$ & $\begin{array}{l}\text { Published online: } \\
\text { April 12, 2011 }\end{array}$ & $\begin{array}{l}\text { O 2011 S. Karger AG, Basel } \\
\text { ISSN 1662-0631 } \\
\text { www.karger.com/crg }\end{array}$ \\
\hline
\end{tabular}

9 Toruner M, Loftus EV Jr, Harmsen WS, Zinsmeister AR, Orenstein R, Sandborn WJ, Colombel JF, Egan LJ: Risk factors for opportunistic infections in patients with inflammatory bowel disease. Gastroenterology 2008;134:929-936.

10 Norgard B, Fonager K, Pedersen L, Jacobsen BA, Sorensen HT: Birth outcome in women exposed to 5-aminosalicylic acid during pregnancy: a Danish cohort study. Gut 2003;52:243-247.

11 Park-Wyllie L, Mazzotta P, Pastuszak A, Moretti ME, Beique L, Hunnisett L, Friesen MH, Jacobson S, Kasapinovic S, Chang D, Diav-Citrin O, Chitayat D, Nulman I, Einarson TR, Koren G: Birth defects after maternal exposure to corticosteroids: prospective cohort study and meta-analysis of epidemiological studies. Teratology 2000;62:385-392.

12 Norgard B, Pedersen L, Christensen LA, Sorensen HT: Therapeutic drug use in women with Crohn's disease and birth outcomes: a Danish nationwide cohort study. Am J Gastroenterol 2007;102:1406-1413.

13 Kainz A, Harabacz I, Cowlrick IS, Gadgil S, Hagiwara D: Analysis of 100 pregnancy outcomes in women treated systemically with tacrolimus. Transpl Int 2000;13(suppl 1):S299-S300.

14 Baumgart DC, Sturm A, Wiedenmann B, Dignass AU: Uneventful pregnancy and neonatal outcome with tacrolimus in refractory ulcerative colitis. Gut 2005;54:1822-1823.

15 Bar Oz B, Hackman R, Einarson T, Koren G: Pregnancy outcome after cyclosporine therapy during pregnancy: a meta-analysis. Transplantation 2001;71:1051-1055. 